\title{
Effect of Si Content on Diffusion Coefficient of Nickel Nitrate in Wet Silica Gel
}

\author{
Ryoji TAKAHASHI, Satoshi SATO, Toshiaki SODESAWA and Hideyo NISHIDA \\ Department of Materials Technology, Faculty of Engineering, Chiba University, 1-33, Yayoi-cho, Inage-ku, Chiba-shi 263-8522
}

\author{
湿潤シリカゲル中における硝酸ニッケルの拡散係数に与えるケイ素量の影響 \\ 高橋亮治 ·佐藤智司 ·袖沢利昭 ·西田英世 \\ 千葉大学工学部物質工学科, 263-8522 千葉市稲毛区弥生町 1-33
}

\begin{abstract}
The liquid-phase diffusion coefficient of nickel nitrate in wet silica gels with different Si content as well as in mesoporous silica gel was measured by the flow-cell method, where absorbance of a gel plate placed in a flow cell was monitored as a function of time. For diffusion in the mesoporous silica gel with pore diameter of 12 $\mathrm{nm}$, the tortuosity was as low as $\mathbf{1 . 2}$, suggesting that the liquid-phase diffusion of nickel nitrate is not restricted in the large mesopores. In contrast, the diffusion coefficient in wet silica gels monotonously decreased with increasing Si content in the gels, and the tortuosity in the wet gel, 1.7-3.5, was larger than that in the mesoporous silica gel. The wet gel is considered to consist of crosslinked polymeric network of silica. The tortuosity in the wet gel would vary depending on the mesh size in the network and on the number of free side chain.

[Received January 24, 2001; Accepted August 9, 2001]
\end{abstract}

Key-words : Pore diffusion, Diffusion coefficient, Wet silica gel, Mesoporous material, Nickel nitrate, Sol-gel

1. Introduction

Sol-gel technology has been widely investigated since 1970 's as a new route to prepare glasses and ceramics. ${ }^{1), 2)}$ Recently, much interest has been focused on the preparation of materials for specific applications, such as drug delivery system, photonics, electronics and catalysis.3)-6) In these preparation of various materials, understanding of kinetics of the solute transportation in liquid phase in wet and porous gels is strongly required to precisely control such properties as release rate of drug, concentration profiles in monolithic gel and distribution of metal particles in supported metal catalysts. The transportation of solutes in a gel generally proceeds by diffusion and its kinetics can be predicted by knowing exact diffusion coefficient in the gel, $D_{\mathrm{p}}$. Therefore, development of convenient method for the measurement of $D_{\mathrm{p}}$ as well as systematic measurement for various solutes in gels with various pore structures is important.

Various methods have been proposed for the measurement of $D_{\mathrm{p}}$. In many cases, $D_{\mathrm{p}}$ was measured for unsteady diffusion. Here, change in the concentration profiles in a gel with time was monitored, and the data were fitted with a solution of Fick's diffusion equation in appropriate initial and boundary conditions to obtain $D_{\mathrm{p}}$. In the measurement, various apparatuses, such as NMR,7) fluorescence ${ }^{8)}$ and UV/ VIS absorption spectroscopies, ${ }^{9)-11)}$ and holographic interferometry, ${ }^{12)}$ were used. Radioactive tracer was also used in some cases. ${ }^{13)}$ However, original improvement in the apparatus is usually necessary for monitoring the concentration change as a function of the position in the gel. Therefore, it has been difficult to generalize the measurement technique for various systems. In some studies, $D_{\mathrm{p}}$ is obtained by monitoring amounts of solute extracted from the gel to outer solvent stirred vigorously ${ }^{14), 15)}$ and by observing the change in average concentration within the gel placed in a solvent.16),17) The former method requires the quantitative analysis of dilute solution, while the later uses only normal UV/VIS spectrometer. Then, the later method, called as a bath-immersion method in this work, would be the most convenience among them. In our previous paper, we have developed a flow-cell method to improve the bathimmersion method, where the diffusion coefficient is calcu- lated from an absorption-decay profile of a wet gel plate held in a flow cell. ${ }^{18)}$ The use of the flow cell makes possible the automatic measurement of change in average concentration within the wet gel. In addition, we have proposed the data processing using exponential law instead of parabolic law. The use of the flow cell as well as exponential function can simplify the measurement of diffusion coefficient for the solute in gel plate.

In this work, we apply the flow-cell method ${ }^{18)}$ to investigate the effect of gel structures, particularly Si content, on the diffusion coefficient of nickel nitrate in the wet gel. Efficiency of the flow-cell method is also tested by comparison with the bath-immersion method.

\section{Experimental}

2.1 Preparation and characterization of gel samples Tetraethoxysilane (TEOS, Shin-Etsu Chemical Co., Japan) and ethyl silicate 40 (ES40, Colcoat Co., USA) were used as silica sources for the preparation of wet silica gels. Either TEOS or ES40 was mixed with aqueous $1 \mathrm{~mol} \mathrm{dm}^{-3}$ nitric acid solution under vigorous stirring. Table 1 lists the starting compositions adopted in this work together with $\mathrm{Si}$ content in the obtained wet gels. After the mixture had become homogeneous, it was sealed in a mold with inside dimensions of $9 \times 9 \times 1.5$ or $1.0 \mathrm{~mm}$. The mold was made with Teflon spacer and two glass plates coated with octadecylsilane. The coating of the glass plate was performed by immersing the plate in a hexane solution of octadecyltrichlorosilane with the concentration of 0.2 mass $\%$ after the plate had been washed in acetone. The mold was closed and held at $50^{\circ} \mathrm{C}$ for $20 \mathrm{~h}$ for gelation. The wet gel thus prepared was immersed in an aqueous solution of nickel nitrate for $1 \mathrm{~d}$ for the measurement of $D_{\mathrm{p}}$ after the internal solution had been throughly exchanged into water.

In the preparation of mesoporous silica gel, a wet gel with appropriate dimensions prepared from an equi-volume mixture of TEOS and aqueous $0.1 \mathrm{~mol} \mathrm{dm}^{-3}$ nitric acid solution at $50^{\circ} \mathrm{C}$ was dried after aging in aqueous $1 \mathrm{~mol} \mathrm{dm}^{-3}$ ammonia solution at $50^{\circ} \mathrm{C}$ for $3 \mathrm{~d}$. The dried gel was heated at $800^{\circ} \mathrm{C}$ for $2 \mathrm{~h}$ to obtain a mesoporous gel. The mesoporous gel was immersed in the aqueous solution of nickel nitrate under vacuum to fill the mesopores with the solution of nick- 
Table 1. Starting Compositions in the Preparation of Wet Silica Gel Samples and Diffusion Coefficients of Nickel Nitrate

\begin{tabular}{cccccccc}
\hline $\begin{array}{c}\text { Si content } \\
\left(\mathrm{mmol} \mathrm{cm} \mathrm{cm}^{-3}\right)\end{array}$ & $\begin{array}{c}\mathrm{TEOS} \\
\left(\mathrm{cm}^{3}\right)\end{array}$ & $\begin{array}{c}\mathrm{ES} 40 \\
\left(\mathrm{~cm}^{3}\right)\end{array}$ & $\begin{array}{c}\mathrm{HNO}_{3} a q^{\mathrm{a}} \\
\left(\mathrm{cm}^{3}\right)\end{array}$ & $\begin{array}{c}\mathrm{H}_{2} \mathrm{O} / \mathrm{Si}-\mathrm{OR} \\
(\mathrm{mol} / \mathrm{mol})\end{array}$ & $\begin{array}{c}V_{\mathrm{f} 1}{ }^{\mathrm{b}} \\
(\%)\end{array}$ & $\begin{array}{c}V_{\mathrm{f} 2}{ }^{\mathrm{c}} \\
(\%)\end{array}$ & $\begin{array}{c}D_{\mathrm{p}}{ }^{\mathrm{d}} \\
\left(\times 10^{-10} \mathrm{~m}^{2} \mathrm{~s}^{-1}\right)\end{array}$ \\
\hline 1.50 & 5 & - & 10 & 6.19 & 91.0 & 96.0 & $6.53 \pm 0.25$ \\
2.25 & 10 & - & 10 & 3.10 & 86.5 & 93.9 & $6.37 \pm 0.20$ \\
3.50 & - & 10 & 10 & 3.26 & 79.0 & 90.4 & $5.07 \pm 0.30$ \\
3.60 & 40 & - & 10 & 0.77 & 78.4 & 90.2 & $4.18 \pm 0.20$ \\
4.67 & - & 20 & 10 & 1.63 & 71.9 & 87.2 & $3.19 \pm 0.20$ \\
5.25 & - & 30 & 10 & 1.09 & 68.5 & 85.7 & $2.91 \pm 0.20$ \\
\hline
\end{tabular}

a $\quad 1 \mathrm{~mol} \mathrm{dm}^{-3}$ aqueous solution.

b Porosity of the wet gel calculated using $d=1.00 \mathrm{~g} \mathrm{~cm}^{-3}$.

c Porosity of the wet gel calculated using $d=2.20 \mathrm{~g} \mathrm{~cm}^{-3}$.

d Diffusion coefficient of nickel nitrate in the wet gels at $25^{\circ} \mathrm{C}$. The value for unbound system, $D_{\text {salt }}$, is $11.70 \times 10^{-10} \mathrm{~m}^{2} \mathrm{~s}^{-1}$ at $25^{\circ} \mathrm{C}[24]$.

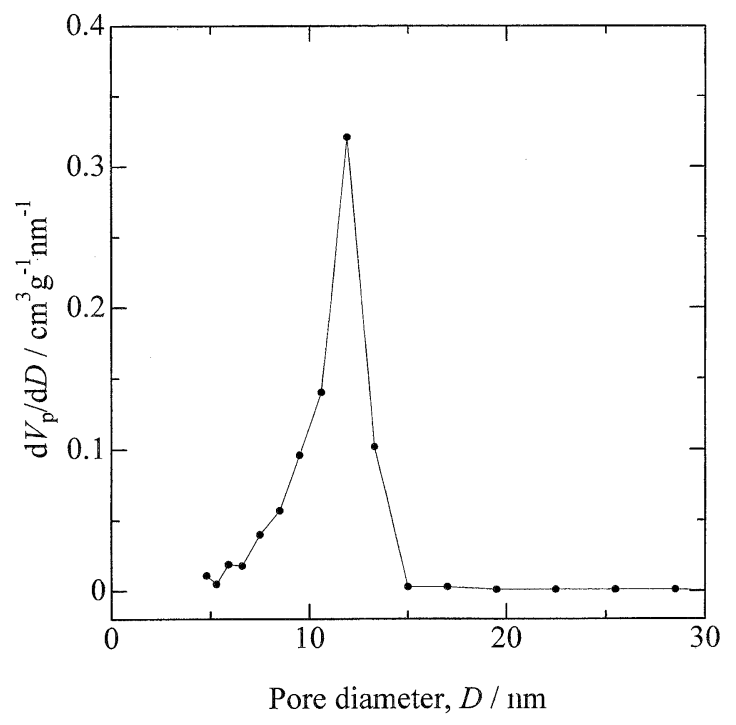

Fig. 1. Pore size distribution of mesoporous silica gel used for the measurement of the diffusion coefficient.

el nitrate for the measurement of $D_{\mathrm{p}}$.

The pore structure of the mesoporous gel was evaluated by nitrogen adsorption at $-196^{\circ} \mathrm{C}$ using automated adsorption apparatus (Omnisorp 100CX, Coulter). The BET and Dollimore-Heal methods ${ }^{19}$ ) were used to analyze the isotherm, and total pore volume was calculated from the adsorption volume at $P / P_{0}>0.95$, as performed in our previous works. ${ }^{20), 21)}$ The pore size distribution of the sample is shown in Fig. 1. BET surface area, peak top in the pore size distribution, pore volume and porosity obtained by assuming that the density of the silica, $d$, is $2.20 \mathrm{~g} \cdot \mathrm{cm}^{-3}$, are listed in Table 2. ${ }^{29} \mathrm{Si}$ MAS NMR spectra for wet gels were measured on a pulse Furrier-transformed NMR spectrometer (DPX300, Bruker Germany) using pulse sequences of high power decoupling. Details of the measurement conditions were reported elsewhere. ${ }^{22)}$

\subsection{Measurement of the diffusion coefficient in the wet and porous gels}

The diffusion coefficients of nickel nitrate in the wet and mesoporous gels were measured by not only the flow-cell18) but also the bath-immersion methods. ${ }^{17)}$ When a gel plate
Table 2. Characteristics of Silica Xerogel Used for the Measurement of $D_{\mathrm{p}}$

\begin{tabular}{ll}
\hline Pore volume $\left(\mathrm{cm}^{3} \mathrm{~g}^{-1}\right)$ & 0.91 \\
peak in pore size distribution $(\mathrm{nm})$ & 12 \\
BET surface area $\left(\mathrm{m}^{2} \mathrm{~g}^{-1}\right)$ & 269 \\
porosity $(\%)$ & 66.7 \\
$D_{\mathrm{p}}\left(\mathrm{m}^{2} \mathrm{~s}^{-1}\right)$ & $(6.43 \pm 0.16) \times 10^{-10}$ \\
tortuosity, $\tau$ & 1.2 \\
\hline
\end{tabular}

containing a solute with concentration of $C_{0}$ is placed in a flow of solvent, the solute is extracted from the gel plate to the outer solvent. If the area of the gel plate is sufficiently larger than the thickness, $2 l$, the solute diffuses only in the direction to the thickness, $x$. Furthermore, if the diffusion coefficient in the unbounded solution is much larger than that in the gel and/or if the external solvent is flowed with sufficiently fast rate, the concentration at the gel surface, at $x=l$ and $-l$, can be equaled to 0 . Under these initial and boundary conditions, the concentration in the gel plate changes according to the following equation. ${ }^{23)}$

$$
\begin{aligned}
\frac{C}{C_{0}}= & \frac{4}{\pi} \sum_{n=0}^{\infty}\left[\frac{(-1)^{n}}{2 n+1} \exp \left\{-\frac{D_{\mathrm{p}}(2 n+1)^{2} \pi^{2} t}{4 l^{2}}\right\}\right. \\
& \left.\times \cos \frac{(2 n+1) \pi x}{2 l}\right]
\end{aligned}
$$

By integrating with $x$ from $-l$ to $l$, we can obtain the change in the average concentration, $C_{\mathrm{av}}$, with time in the gel.

$$
\frac{C_{\mathrm{av}}}{C_{0}}=\frac{8}{\pi^{2}} \sum_{n=0}^{\infty}\left[\frac{1}{(2 n+1)^{2}} \exp \left\{-\frac{D_{\mathrm{p}}(2 n+1)^{2} \pi^{2} t}{4 l^{2}}\right\}\right]
$$

In both the flow-cell ${ }^{18)}$ and the bath-immersion ${ }^{17)}$ methods, the change in the absorbance, $A$, of the solute in the gel plate is monitored instead of $C_{\mathrm{av}}$ to obtain $D_{\mathrm{p}}$. The values of $A$ can be related with the concentration of the solute by the Lambert-Beer law: $A=\varepsilon 2 l C$, where $\varepsilon$ is molar absorptivity. Then, we can substitute $A$ and $A_{0}$ for $C_{\mathrm{av}}$ and $C_{0}$, respectively.

At the initial stage of diffusion, the equation can be approximated with parabolic function. ${ }^{17), 18), 23)}$ 


$$
1-\frac{A}{A_{0}}=\frac{4}{(2 l)} \sqrt{\frac{D_{\mathrm{p}}}{\pi}} \times t^{1 / 2}
$$

Then, we can obtain $D_{\mathrm{p}}$ from the slope of the plot of $(1-A /$ $\left.A_{0}\right)$ vs. $t^{1 / 2}$. At the late stage, on the other hand, the Eq. (2) can be approximated with exponential function. ${ }^{18)}$

$$
A=A_{0} \frac{8}{\pi^{2}} \exp \left(-\frac{\pi^{2} D_{\mathrm{p}} t}{4 l^{2}}\right)
$$

Then, we can also obtain $D_{\mathrm{p}}$ from the slope of $\log (A)$ vs. $t$.

In the flow-cell method, a flow cell with inside dimensions of $10 \times 10 \times 40 \mathrm{~mm}$ was set in a UV/VIS spectrometer (UV-100-02, Shimadzu). Here, the flow cell was made using commercial polystylene cell, glass pipe, and silicone rubber. A gel containing nickel nitrate solution was held in the flow cell, and monochromatic light, which was stopped down with pin-hole slit with diameter of ca. $1 \mathrm{~mm}$, was irradiated at the center of the gel plate. Then, the change in the absorbance at $394 \mathrm{~nm}$ with time due to diffusion was monitored under the flow of external solvent. Further information on the measurement technique of the flow cell method was described elsewhere. ${ }^{18)}$

In the bath-immersion method, ${ }^{17)}$ a gel containing a solution of nickel nitrate with an appropriate concentration was placed in a water bath. The gel was picked up at every appropriate time, and its absorption spectrum at each time was recorded with UV/VIS spectrometer (UV1600PC, Shimadzu) after droplets of liquid on the gel surface had been wiped. The absorbance-time data were obtained from intensities of absorption bands at 394 and $301 \mathrm{~nm}$ in the spectra.

The absorbance-time data were acquired at $25^{\circ} \mathrm{C}$, and fitted with Eq. (3) or Eq. (4) to obtain $D_{\mathrm{p}}$.

\section{Results and discussion}

Figure 2 shows changes in absorption spectra with time for a wet gel containing aqueous solution of nickel nitrate measured by the bath-immersion method. The absorption bands at 394 and $301 \mathrm{~nm}$ are ascribed to $d-d$ transition in $\mathrm{Ni}^{2+}$ (hexa-aqua nickel ion) and $n-\pi^{*}$ transition in $\mathrm{NO}_{3}{ }^{-}$, respectively. The spectrum for the wet gel well agrees with that for unbounded solution of nickel nitrate, suggesting that the coordination structures of $\mathrm{Ni}^{2+}$ and $\mathrm{NO}_{3}{ }^{-}$in the wet gel are essentially the same as those in bulk solution. ${ }^{18)} \mathrm{We}$ preliminarily ensured that the intensity of the absorption bands at 394 and $301 \mathrm{~nm}$ proportionally increases with the concentration of nickel nitrate, i.e. the Lambert-Beer law is satisfied. By immersing the wet gel in water, both the absorption bands gradually decrease with the progress of diffusion.

In Fig. 3, $\left(1-A / A_{0}\right)$ values obtained by the flow-cell and the bath-immersion methods are plotted against $t^{1 / 2}$, where $A$ values for the bath immersion are obtained from peak top of the absorption bands at 301 and $394 \mathrm{~nm}$ in each spectrum in Fig. 2. Although sigmoidal dependence is recognized in all the data, linear fitting lines passing an origin can be drown. The diffusion coefficient is calculated from a slope of the each fitting line according to Eq. (3). The solid and broken lines in the Fig. 3 represent theoretical decay behaviors calculated from Eq. (2) using obtained diffusion coefficient and thickness of the gel plates used in the experiments.

In our previous work, we have attributed the origin of the sigmoidal dependence to the deviation in boundary conditions, i.e. the approximation of $C=0$ at $x=l$ and $-l$ is not satisfied at the initial stage because of the formation of stagnant layer at the surface of the gel plate. ${ }^{18)}$ When the difference between diffusion coefficient in unbound system and that in gel is not so large and the mass flow of external sol-

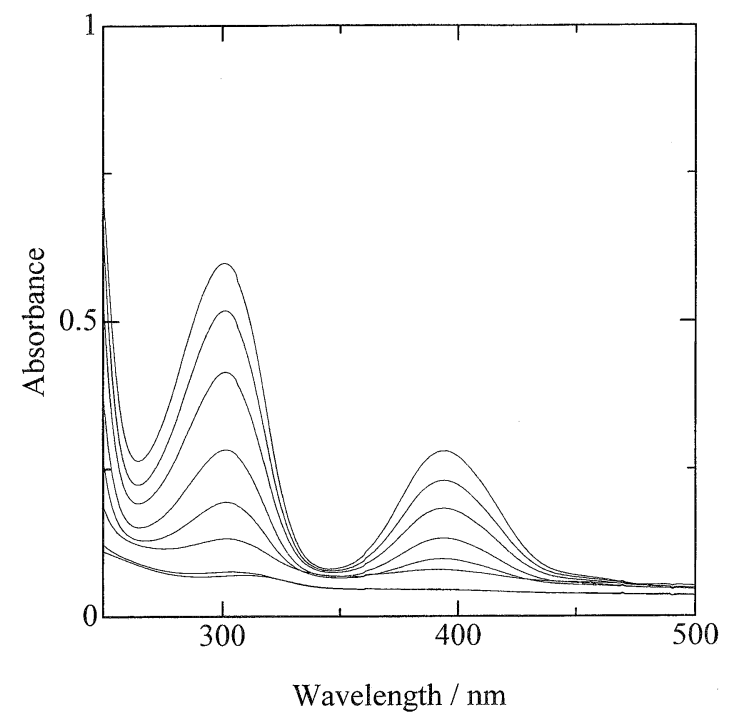

Fig. 2. Changes in the UV/VIS absorption spectra of the wet gel with the immersion time in water. The spectra were measured at immersion time of $0,35,60,135,245,480,1005$ and $1490 \mathrm{~s}$, which are shown from the top curve downwards. Si content, $3.50 \mathrm{mmol}$ $\mathrm{cm}^{-3} ; 2 l, 1.0 \mathrm{~mm}$.

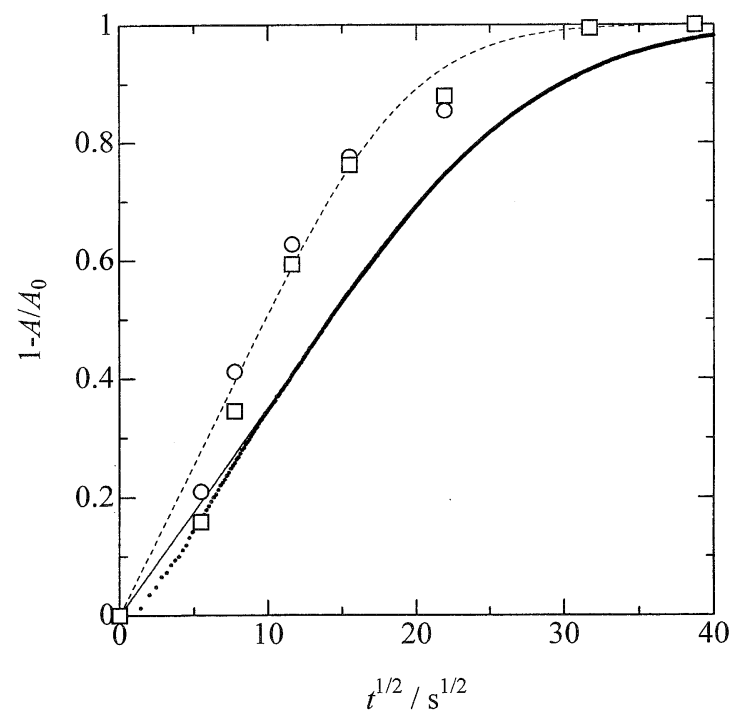

Fig. 3. $\left(1-A / A_{0}\right)$ vs. $t^{1 / 2}$ plots for the data obtained by the bathimmersion and the flow-cell (small dots) methods. Values of $A$ for the bath immersion were obtained from the peak tops in the absorption bands at $394(\bigcirc)$ and $301 \mathrm{~nm}(\square)$ in Fig. 2. The solid line represents theoretical change calculated from Eq. (2) using $2 l=1.5$ $\mathrm{mm}$ and $D_{\mathrm{p}}=5.0 \times 10^{-10} \mathrm{~m}^{2} \cdot \mathrm{s}^{-1}$, and the broken one represents that using $2 l=1.0 \mathrm{~mm}$ and $D_{\mathrm{p}}=5.0 \times 10^{-10} \mathrm{~m}^{2} \cdot \mathrm{s}^{-1}$.

vent is substantially slow, the concentration at the surface of the gel plate can not be equal to 0 . In addition, the extraction rate from the gel at the initial stage of the diffusion is much faster than that at the late stage. Therefore, we have pointed out that the use of the data at the late stage is preferable in the flow cell method, because the flow rate of the external solvent can not be increased so much. ${ }^{18)}$ Clearly, the deviation in boundary conditions also occurs in the data obtained in the bath-immersion method.

Figure 4 shows changes in logarithm of $A$ with $t$ for the 


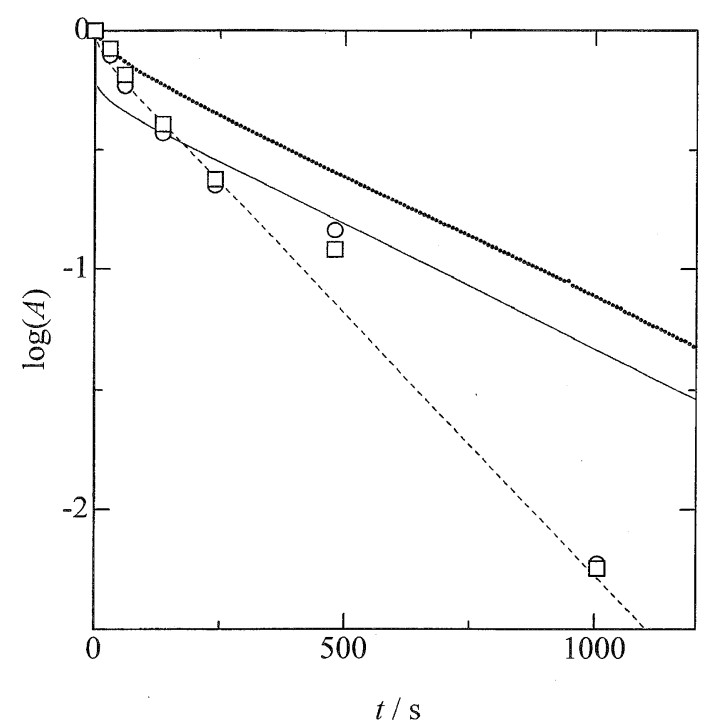

Fig. 4. $\log (A)$ vs. $t$ plots for the data same as in Fig. 3.

data same as shown in Fig. 3. A good linearity is recognized in this plot. The diffusion coefficients can be calculated from the slopes of the fitting lines by using Eq. (4). In Fig. 4, theoretical lines are also drown. The theoretical line and the data measured by the flow-cell method well coincide each other. Namely, the boundary conditions used to derive the solution of the diffusion equation are approximately satisfied in the measurement at the late stage of diffusion. In contrast, deviation in the data point from the theoretical line is relatively large for the bath-immersion data. Because the data number is restricted in the bath immersion, the data error would be significant. In addition, the bath-immersion method has other disadvantages. Firstly, one has to handle a fragile wet gel in measurement of absorption spectra which would be a cause of the damage of the gel surface. Secondly, it is difficult to set the gel plate in the spectrometer as same as before. Slight differences in the angle of the gel plate against the incident beam and in the position at which the incident beam is focused would be origins of the experimental error in the absorption data. Because of these disadvantages, the dispersion of the data points in the bath-immersion method would become larger than that in the flow-cell method.

$D_{\mathrm{p}}$ values obtained by different methods for a wet gel with Si content of $3.50 \mathrm{mmol} \mathrm{cm} \mathrm{cm}^{-3}$ are summarized in Table 3. Although the dispersion in the data points in each measurement is larger in the bath immersion, the experimental error in the obtained values of $D_{\mathrm{p}}$ is comparable among the methods. The $D_{\mathrm{p}}$ values also coincide each other within the experimental error in spite of the deviation in the boundary conditions at the initial stage. Then, it would be said that the accuracy of the $D_{\mathrm{p}}$ values obtained by the flow-cell method is as high as those by the bath-immersion method, and the exponential function can be used in the data processing for the data obtained by the both methods. However, the use of the flow-cell method has large advantage because the automated procedure substantially decreases the difficulties in the systematic measurements. The use of the bath-immersion method and the data processing with parabolic plot at the initial stage would be the most effective when the diffusion coefficient in the wet gel is substantially small, because long measurement time is required to obtain the data at the late stage for exponential fitting.

In Table 3, it was also found that the diffusion coefficient
Table 3. Diffusion Coefficients of Nickel Nitrate in the Wet Gel with Si Content of $3.50 \mathrm{mmol} \mathrm{cm}^{-3}$

\begin{tabular}{lc}
\hline measurement method $^{\mathrm{a}}$ & $D_{\mathrm{p}}\left(\times 10^{-10} \mathrm{~m}^{2} \mathrm{~s}^{-1}\right)$ \\
\hline FC - exponential $(394 \mathrm{~nm})$ & $5.07 \pm 0.30$ \\
BI - exponential $(394 \mathrm{~nm})$ & $5.05 \pm 0.20$ \\
BI - parabolic $\quad(394 \mathrm{~nm})$ & $4.86 \pm 0.20$ \\
BI - exponential $(301 \mathrm{~nm})$ & $4.98 \pm 0.30$ \\
BI - parabolic $\quad(301 \mathrm{~nm})$ & $5.28 \pm 0.30$ \\
\hline
\end{tabular}

a Methods of measurement of $A-t$ data and of data processing. FC, the flow cell method; BI, the bath immersion method. The numbers in the parentheses are the wavelength of the absorption bands.

of $\mathrm{Ni}^{2+}$ is the same as that of $\mathrm{NO}_{3}{ }^{-}$. The self-diffusion coefficients of $\mathrm{Ni}^{2+}$ and $\mathrm{NO}_{3}{ }^{-}$ions in unbounded aqueous solution are reported to be 6.61 and $19.20 \times 10^{-10} \mathrm{~m}^{2} \cdot \mathrm{s}^{-1}$ at $25^{\circ} \mathrm{C}$, respectively. ${ }^{24}$ ) In the present experimental conditions, both the $\mathrm{Ni}^{2+}$ and $\mathrm{NO}_{3}{ }^{-}$ions diffuse concurrently to maintain a charge balance. Then, the diffusion coefficient in the gel experimentally measured should be compared with that of salt in the unbound system, $D_{\text {salt }}$, instead of those of individual ions. $D_{\text {salt }}$ is represented as the following equation. ${ }^{24)}$

$$
D_{\text {salt }}=\frac{\left(z_{+}+\left|z_{-}\right|\right) \times D_{+} \times D_{-}}{\left(z_{+} \times D_{+}+\left|z_{-}\right| \times D_{-}\right)}
$$

Here, $z$ represents ion valence. $D_{\text {salt }}$ of nickel nitrate is calculated to be $11.70 \times 10^{-10} \mathrm{~m}^{2} \cdot \mathrm{s}^{-1}$

The $D_{\mathrm{p}}$ values in various wet gels and mesoporous gel, which are measured by the flow-cell method, are listed in Tables 1 and 2 . In the porous media, factors restricting diffusion of solute are porosity, $V_{\mathrm{f}}$, and tortuosity, $\tau$, which is introduced as a structural factor relating to the continuity of pores and/or roughness of the pore surface. ${ }^{25)}$ Then, the diffusion coefficient in the porous media can be related to that in the unbound system as follows.

$$
D_{\mathrm{p}}=\frac{V_{\mathrm{f}}}{\tau} D_{\text {salt }}
$$

For the mesoporous silica gel with pore size of $12 \mathrm{~nm}, D_{\mathrm{p}}$ is $6.43 \times 10^{-10} \mathrm{~m}^{2} \cdot \mathrm{s}^{-1}$ and $\tau$ is estimated to be 1.2 (Table 2). The small value of tortuosity indicates that diffusion resistance of nickel nitrate in the mesoporous silica with pore diameter of $12 \mathrm{~nm}$ is negligibly small. Namely, $D_{\mathrm{p}}$ in the pores with diameter of $12 \mathrm{~nm}$ is largely determined by $V_{\mathrm{f}}$.

For the wet silica gels listed in Table $1, D_{\mathrm{p}}$ decreases with increasing Si content in the gel. One of the reason of the decrease in $D_{\mathrm{p}}$ is the decrease in $V_{\mathrm{f}}$ with the increase in silica content. However, it is difficult to estimate the dependence of tortuosity on silica content because we can not determine the exact values of the porosity due to uncertainty in the density of the silica gel skeleton with a large number of silanols. Then, we assume that the density of the silica gel skeleton would be in the range between 2.2 , the density of silica glass, and $1.0 \mathrm{~g} \cdot \mathrm{cm}^{-3}$, the density of water. The latter assumption is based on the fact that the silica phase precipitates when phase separation occurs in a sol-gelreacting solution. ${ }^{26)}$ From the values for density together with $\mathrm{Si}$ content, we can assume the porosity in the wet gel within a particular error bar (Table 1). 


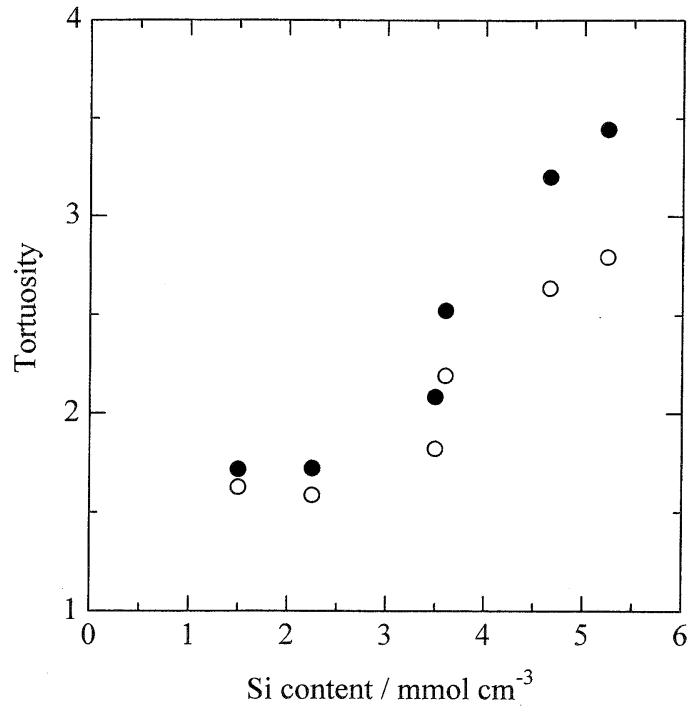

Fig. 5. Dependence of tortuosity on the Si content in the wet gel. $\bigcirc$, for $V_{\mathrm{f} 1} ; \mathbf{O}$, for $V_{\mathrm{f} 2}$ in Table 1 .

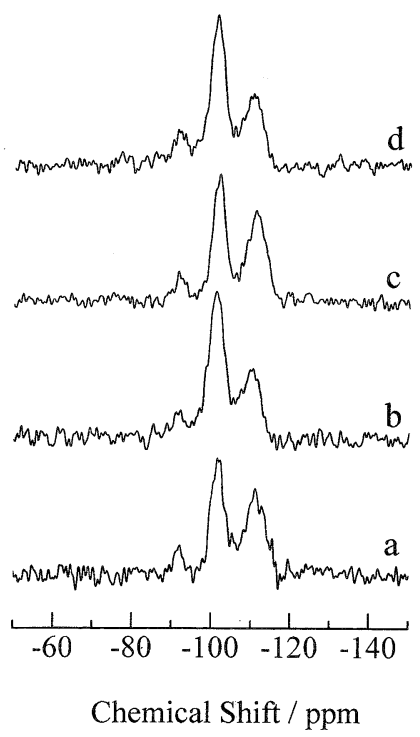

Fig. 6. ${ }^{29} \mathrm{Si}$ MAS NMR spectra of the wet gel samples containing $\mathrm{Si}$ of (a) 2.25 , (b) 3.60 , (c) 3.50 and (d) $5.25 \mathrm{mmol} \mathrm{cm}^{-3}$. MAS rate, $4 \mathrm{kHz}$, number of scans, 256 ; pulse, $30^{\circ}$; pulse interval, $100 \mathrm{~s}$.

Figure 5 shows the dependence of tortuosity on Si content in the wet gels. The tortuosity clearly increases with increasing Si content. Here, it should be noted that the tortuosity in the wet gel is higher than that in the mesoporous gel (Table 2). To clarify the origin of the result, ${ }^{29} \mathrm{Si}$ MAS NMR spectra of the wet gel with different Si content were measured (Fig. 6). In the spectra, the peaks at ca. -90 , -100 and -110 ppm have been ascribed to $Q^{2}, Q^{3}$ and $Q^{4}$ silicons, respectively. ${ }^{2}$ Here, $Q^{n}$ indicates a formula of $\mathrm{Si}(\mathrm{OSi})_{n}(\mathrm{OR})_{4-n}$ where $\mathrm{R}$ is alkyl or hydrogen. The fractions of $Q^{4}$ in the samples with Si content of 3.60 and 5.25 $\mathrm{mmol} \mathrm{cm} \mathrm{cm}^{-3}$ are smaller than those in the other samples. As these samples were prepared with compositions at low $\mathrm{H}_{2} \mathrm{O}$ content, the $\mathrm{H}_{2} \mathrm{O} / \mathrm{Si}-\mathrm{OR}$ ratios are as small as 1 (Table 1 ). The small $\mathrm{H}_{2} \mathrm{O}$ content leads incomplete hydrolysis of $\mathrm{Si}-\mathrm{OR}$ groups and less-developed $\mathrm{Si}-\mathrm{O}-\mathrm{Si}$ network. There-
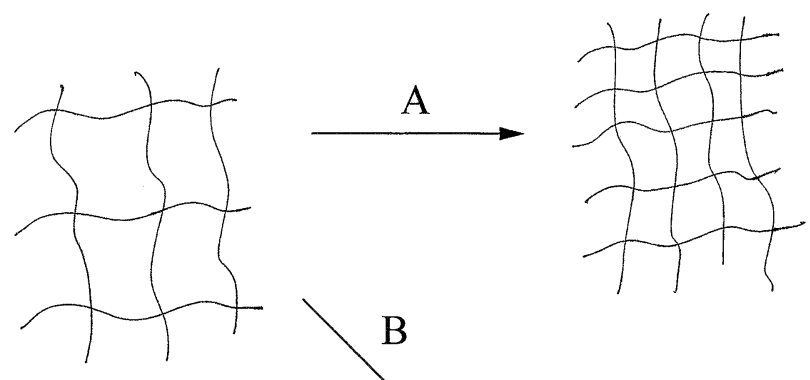

B

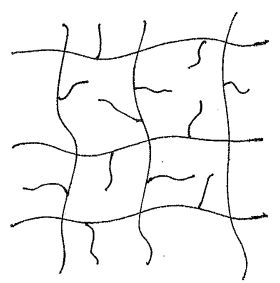

Fig. 7. Schematic drawing for change in the network structure of wet silica gel (A) with the increase in Si content and (B) with the decrease in $\mathrm{H}_{2} \mathrm{O} / \mathrm{Si}-\mathrm{OR}$ ratio.

fore, the $Q^{4}$ proportion of these samples becomes smaller. However, no significant difference in $Q^{n}$ distribution is observed for the gel prepared with different raw materials, TEOS and ES40, as long as the $\mathrm{H}_{2} \mathrm{O} / \mathrm{Si}-\mathrm{OR}$ ratio is comparable.

It has been known that a sol-gel-derived wet silica gel is composed of polymeric silica network with fractal nature rather than particle aggregates when the gel is prepared using acid as a catalyst for hydrolysis and condensation. ${ }^{2)}$ If the Si content in the gel increases with retaining $Q^{n}$ distribution, mesh size in the crosslinked polymeric network would decrease as illustrated in Fig. 7. Kunetz and Hench have reported that the tortuosity in porous silica gels for the diffusion of $\mathrm{Cr}^{3+}$ ion remarkably increases with the decrease in pore size. ${ }^{17)}$ One of the reason for the increase in the tortuosity with the increase in Si content (Fig. 5) would be the decrease in mesh size of silica network in the wet gel. In addition, gels prepared at low $\mathrm{H}_{2} \mathrm{O} / \mathrm{Si}-\mathrm{OR}$ ratio show larger tortuosity (Fig. 5 and Table 1). For example, the difference in tortuosity of the gels with $\mathrm{Si}$ content between 3.50 and $3.60 \mathrm{mmol} \mathrm{cm}^{-3}$ is as high as 0.5 . As observed by ${ }^{29} \mathrm{Si}$ MAS NMR (Fig. 6), Si-O-Si network is less developed in a gel prepared at low $\mathrm{H}_{2} \mathrm{O} / \mathrm{Si}-\mathrm{OR}$ ratio. Then, number of free silica side chain bonded to crosslinked network would increase (Fig. 7). The side chains possibly act as obstacles for the diffusion in solvent phase. Thus, it is considered that tortuosity in a wet gel varies depending on Si content in the gel as well as $\mathrm{H}_{2} \mathrm{O} / \mathrm{Si}-\mathrm{OR}$ ratio in the preparation.

\section{Conclusion}

Diffusion coefficients of nickel nitrate in wet silica gels with different Si content and in mesoporous silica gel were measured by the flow-cell method. In the mesoporous silica gel with pore diameter of $12 \mathrm{~nm}$, the tortuosity is as low as 1.2 , suggesting that diffusion of nickel nitrate is not restricted in the relatively large mesopores. On the other hand, the diffusion coefficient in the wet silica gel decreases monotonously and tortuosity increases from 1.7 to 3.5 with increasing the Si content in the gel. The wet gel is formed with polymeric network of silica, and the increase in the $\mathrm{Si}$ content leads the decrease in mesh size of the silica network, which would be an origin of the increase in the tortuosity of the wet gel with $\mathrm{Si}$ content. In addition, a gel pre- 
pared at low $\mathrm{H}_{2} \mathrm{O} / \mathrm{Si}-\mathrm{OR}$ ratio also showed high tortuosity probably because of the increase in free side chain in the crosslinked gel network.

Acknowledgment The present work was partially supported by Grant-in-Aid for Encouragement of Young Scientists (11750580), and Grant-in Aid for Scientific Research C (12650075) from the Japan Society for the Promotion of Science.

\section{References}

1) Sakka, S., "Science of Sol-Gel Method," Agne Shofusha, Tokyo (1988) [in Japanese].

2) Brinker, C. J. and Scherer, G. W., "Sol-Gel Science," Academic Press (1990)

3) Sakka, S., “Application of Sol-Gel Method,” Agne Shofusha, Tokyo (1997) [in Japanese].

4) Cauqui, M. A. and Rodrigues-Izquierdo, J. M., J. Non-Cryst. Solids, 147 \& 148, 724-38 (1992).

5) Takahashi, R., Sato, S., Sodesawa, T., Kato, M. and Yoshii, T., Chem. Lett., 1999, 305-06 (1999).

6) Takahashi, R., Sato, S., Sodesawa, T., Kato, M. and Yoshida, S., J. Sol-Gel Sci. Technol., 19, 715-18 (2000).

7) Walderhaug, H. and Nystroem, B., J. Phys. Chem. B, 101, 1524-27 (1997).

8) Yilmaz, Y. and Pekcan, O., Polymer, 39, 5351-57 (1998).

9) Koone, N. D. and Zerda, T. W., J. Non-Cryst. Solids, 183, 243-51 (1995).

10) Koone, N. D., Guo, J. D. and Zerda, T. W., J. Non-Cryst. Solids, 211, 150-57 (1997).

11) Dunmire, E. N., Plenys, A. M. and Katz, D. F., J. Controlled Release, 57, 127-40 (1999).
12) Gits-Leon, S., Lefaucheux, F. and Robert, M. C., J. Cryst. Growth, 84, 155-62 (1987).

13) Koone, N. D., Shao, Y. and Zerda, T. W., J. Phys. Chem., 99, 16976-81 (1995).

14) Sieminska, L. and Zerda, T. W., J. Phys. Chem., 100, 4591-97 (1996)

15) Lakatos, I. and Lakatos-Szabo, J., Colloids Surfaces A: Physicochem. Eng Aspects, 141, 425-34 (1998).

16) Kunetz, J. M., West, J. K. and Hench, L. L., "Chemical Processing of Advanced Materials," Ed. Hench, L. L. and West, J. K., John Wiley \& Sons, Inc. (1992) pp. 115-22.

17) Kunetz, J. and Hench, L., J. Am. Ceram. Soc., 81, 877-84 (1998).

18) Takahashi, R., Sato, S., Sodesawa, T. and Kamomae, Y. Phys. Chem. Chem. Phys. 2, 1199-204 (2000).

19) Dollimore, D. and Heal, G. R., J. Appl. Chem., 14, 109-14 (1964).

20) Takahashi, R., Sato, S., Sodesawa, T., Kawakita, M. and Ogura, K., J. Phys. Chem. B, 104, 12184-91 (2000).

21) Nakamura, N., Takahashi, R., Sato, S., Sodesawa, T. and Yoshida, S., Phys. Chem. Chem. Phys., 2, 4983-90 (2000).

22) Takahashi, R., Sato, S., Sodesawa, T., Suzuki, M. and Ogura, K., Bull. Chem. Soc. Jpn., 73, 765-74 (2000).

23) Crank, J., "The Mathematics of Diffusion," Oxford University Press, Oxford (1975) Ch. 4.

24) "Handbook of Chemistry and Physics," 79th ed., Ed. Lide, D. R., CRC Press (1998) pp. 5-93.

25) Smith, J. M., "Chemical Engineering Kinetics," 3rd ed., McGraw-Hill, New York (1981) p. 465.

26) Nakanishi, K., J. Porous Materials, 4, 67-112 (1997). 